Marquette University

e-Publications@Marquette

$1-1-2013$

\title{
Functional Implications of Impaired Control of Submaximal Hip Flexion Following Stroke
}

Allison S. Hyngstrom

Marquette University, allison.hyngstrom@marquette.edu

Sandra K. Hunter

Marquette University, sandra.hunter@marquette.edu

Accepted version. Muscle \& Nerve, Vol. 49, No. 2 (November 2013): 225-232. DOI. (C) 2013 John Wiley \& Sons, Inc. Used with permission. 


\title{
Functional Implications of Impaired Control of Submaximal Hip Flexion Following Stroke
}

\author{
Allison S. Hyngstrom \\ Department of Physical Therapy, Marquette University, \\ Milwaukee, WI \\ Henry R. Kuhnen \\ Department of Biomedical Engineering, Marquette University, \\ Milwaukee, WI \\ Kiersten M. Kirking \\ Department of Physical Therapy, Marquette University, \\ Milwaukee, WI \\ Sandra K. Hunter \\ Department of Physical Therapy, Marquette University, \\ Milwaukee, WI
}

\begin{abstract}
Introduction: We quantified submaximal torque regulation during low to moderate intensity isometric hip flexion contractions in individuals with stroke and the associations with leg function. Methods: Ten participants with chronic stroke and 10 controls performed isometric hip flexion contractions at $5 \%$, $10 \%, 15 \%, 20 \%$, and $40 \%$ of maximal voluntary contraction (MVC) in
\end{abstract}

Muscle \& Nerve, Vol 49, No. 2 (November 2013): pg. 225-232. DOI. This article is (C Wiley and permission has been granted for this version to appear in e-Publications@Marquette. Wiley does not grant permission for this article to be further copied/distributed or hosted elsewhere without the express permission from Wiley. 
paretic, nonparetic, and control legs. Results: Participants with stroke had larger torque fluctuations (coefficient of variation, CV), for both the paretic and nonparetic legs, than controls $(P<0.05)$ with the largest CV at $5 \%$ MVC in the paretic leg $(P<0.05)$. The paretic CV correlated with walking speed $\left(r^{2}=0.54\right)$ and Berg Balance Score $\left(r^{2}=0.40\right)$. At 5\% MVC, there were larger torque fluctuations in the contralateral leg during paretic contractions compared with the control leg. Conclusions: Impaired low-force regulation of paretic leg hip flexion can be functionally relevant and related to control versus strength deficits poststroke.

\section{Abbreviations}

BMI body mass index

CV coefficient of variation

MET metabolic equivalent

MVC maximal voluntary contraction

RMSE root mean square error

After a stroke, leg function is often quantified by the ability of paretic musculature, such as the hip flexors, to generate maximal forces. However, many individuals with stroke struggle chronically with motor tasks $\frac{1-4}{1}$ that require controlled submaximal force generation. For example, regulation of submaximal hip flexion force is important for controlled advancement of the leg during swing, body weight support during single leg stance, and stabilization of the leg and trunk

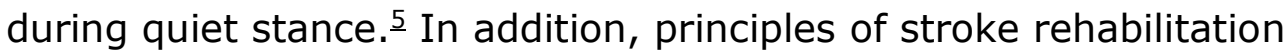
emphasize mastery of task-specific exercises ${ }^{6}$ that require submaximal force generation. Despite the neurophysiological and clinical implications, the ability to regulate submaximal forces of the paretic leg for locomotion is not well characterized.

In previous studies of neurologically intact participants, submaximal force regulation was examined with metrics such as the magnitude, error, and frequency of force fluctuations during submaximal contractions, and it can vary with several factors, including the muscle, load level, and age. $\frac{7-12}{12}$ Notably, in neurologically intact older adults, impairments in hip flexion and hip extension torque steadiness (i.e., magnitude of the torque fluctuations) and error (i.e., offset from target torque) were greater at very low load levels (5\% of MVC) compared with younger adults. $\frac{13}{}$ Furthermore, low force regulation (i.e., $<10 \% \mathrm{MVC}$ ) of the leg muscles was a strong predictor of function in older adults. $\frac{14-16}{}$ Analysis of force fluctuation frequency with age indicates that sensory processing (visual) can contribute to impaired force control in older adults. $\frac{17}{1}$ Together, these data suggest that, for older adults, activities that require control of relatively lower

Muscle \& Nerve, Vol 49, No. 2 (November 2013): pg. 225-232. DOI. This article is (C) Wiley and permission has been granted for this version to appear in e-Publications@Marquette. Wiley does not grant permission for this article to be further copied/distributed or hosted elsewhere without the express permission from Wiley. 
loads would be more difficult to perform due to impaired force control, possibly related to sensory interference rather than weakness. This information is relevant to the stroke population, because motor impairment is often characterized by baseline strength quantified from brief maximal voluntary contractions. Given that many activities of daily living require control of submaximal forces by the hip flexors (e.g., walking and transfers) impaired submaximal force regulation would likely interfere with mobility. Importantly, evidence in neurologically intact participants has shown that training interventions can improve force control $\frac{18,19}{1}$ and provide the potential for new therapeutic interventions after stroke that aim to improve force control and leg function.

In general, there is a need for further information regarding submaximal force regulation in neurologically involved patient populations and their relevance to motor function, especially in leg muscles required for locomotion. Previous work that looked specifically at force fluctuations during submaximal contractions focused on populations with tremor-associated disorders such as Parkinson disease, essential tremor, cerebellar disorders, and multiple sclerosis. $\underline{20-25}$ Much of this work has examined force regulation in the upper extremity and relationships with overall function. Little is known about the lower extremity in the stroke population.

After stroke, submaximal force regulation of the lower extremities could be altered due to a damaged motor cortex and increased activity from subcortical motor centers $\frac{26-31}{2}$ that are known to innervate larger proximal musculature (higher motoneuron to muscle fiber ratio) and could distort descending inputs. Few studies, however, have examined submaximal force regulation in the lower extremities after stroke. Chow and Stokic (2011) showed knee extensor steadiness was less for participants after stroke (greater force fluctuations) than controls during brief isometric contractions (20 to $50 \%$ maximum strength), and there was no relationship with the level of impairment for clinical assessment of participants with stroke (Fugl Meyer or Rivermead Mobility Index). $\underline{32}$ The authors attributed the lack of association between steadiness and clinical measurements to the sample bias (high functioning within a month poststroke). As is seen in aging populations, it could be that associations between submaximal force regulation and functional relationships are muscle specific.

Muscle \& Nerve, Vol 49, No. 2 (November 2013): pg. 225-232. DOI. This article is (C) Wiley and permission has been granted for this version to appear in e-Publications@Marquette. Wiley does not grant permission for this article to be further copied/distributed or hosted elsewhere without the express permission from Wiley. 
Control of force by other muscle groups of the paretic leg, such as the hip flexors, may be more predictive of overall leg function.

Why is it important to understand submaximal force regulation of paretic hip flexors? In the neurologically intact system, evidence from animal, $\underline{33-37}$ human, $\underline{38}$ and neurocomputational models $\underline{39}$ demonstrate the importance of hip muscle function, in particular hip flexors and extensors, in neural control of locomotion and postural responses. .40 After stroke, distal muscles of the ankle are often affected profoundly, resulting in permanent bracing. $\underline{41}$ This necessarily places increased reliance on more proximal muscles, such as hip flexors, $\underline{37,42,43}$ to advance and stabilize the paretic leg. While deficits in hip flexion power during walking 44 are associated with impaired walking function, there is little known about the regulation of force during submaximal contractions for hip flexors. Previous examinations of submaximal force generation of the leg after stroke quantified the peak magnitude and timing of peak force production at 1 or more joints $\underline{30,45,46}$ during discrete tasks or global outputs during walking that are a result of impaired submaximal force generation (e.g., step asymmetry). Given the importance of hip flexors in force generation for walking and balance and increased reliance on this muscle group after stroke, regulation of hip flexors might be more closely associated with measures of function, especially in more impaired individuals.

The purpose of this study was twofold: (1) to quantify load-level dependent differences in hip flexion torque steadiness and error between the paretic, nonparetic, and control legs, and (2) to relate impairments in submaximal force regulation to clinical measurements of function. We hypothesized that torque fluctuations of the paretic leg would be: (1) less steady (i.e., larger torque fluctuations) and have larger error (greater offset from target torque) at the lowest load level compared with the nonparetic and control legs, and (2) negatively correlated with clinical measures of self- selected walking speed and balance. In addition, we used frequency analysis of torque fluctuations to gain insight into possible mechanisms of impairments in paretic torque regulation.

Muscle \& Nerve, Vol 49, No. 2 (November 2013): pg. 225-232. DOI. This article is (C Wiley and permission has been granted for this version to appear in e-Publications@Marquette. Wiley does not grant permission for this article to be further copied/distributed or hosted elsewhere without the express permission from Wiley. 


\section{Materials and Methods}

\section{Participants}

Participants included 10 individuals with a history of stroke (cortical strokes $>6$ months; 5 men and 5 women; mean age \pm SD: $59 \pm 11$ years; physical activity level $=17.7 \pm 8$ Met-h/wk; body mass index [BMI]: $24.9 \pm 3$; see Table 1 for other characteristics) and 10 neurologically intact age and gender matched controls (59 \pm 12 years; physical activity level $=18.0 \pm 20$ Met-h/wk; BMI = $25 \pm 3)$. Metabolic equivalent (MET) levels were estimated through a questionnaire. 47 Per reported history, all participants had suffered a single stroke with unilateral sensory and motor deficits. Participants were excluded if they reported any untreated cardiovascular or orthopedic conditions, decubitis ulcerations, osteoporosis, or had cognitive impairments that limited their ability to follow instructions or provide informed consent. All participants could ambulate independently on level surfaces without an orthosis or assistive device except 1 participant, who ambulated with a large base quad cane and articulated orthosis. At the time of the study, none of the participants with a history of stroke were taking oral antispasticity medications or had received botulinum toxin injections in the leg within 3 months of the date of this study. All experimental procedures were approved by the Marquette University Institutional Review Board.

Table 1. Characteristics of participants with a history of stroke.

$\begin{array}{cccccc}\text { Participant } & \begin{array}{c}\text { Age } \\ \text { (year) }\end{array} & \text { Gender } & \begin{array}{c}\text { Side } \\ \text { affected }\end{array} & \begin{array}{c}\text { LE Fugl } \\ \text { Meyer }\end{array} & \begin{array}{c}\text { Months } \\ \text { poststroke }\end{array} \\ \text { S1 } & 63 & \text { M } & \text { R } & 28 & 37 \\ \text { S2 } & 45 & \text { M } & \text { L } & 22 & 72 \\ \text { S3 } & 62 & \text { W } & \text { L } & 25 & 85 \\ \text { S4 } & 46 & \text { M } & \text { R } & 22 & 102 \\ \text { S5 } & 74 & \text { W } & \text { R } & 34 & 19 \\ \text { S6 } & 60 & \text { W } & \text { L } & 19 & 317 \\ \text { S7 } & 78 & \text { W } & \text { L } & 21 & 96 \\ \text { S8 } & 52 & \text { W } & \text { R } & 31 & 225 \\ \text { S9 } & 57 & \text { M } & \text { R } & 29 & 80 \\ \text { S10 } & 51 & \text { M } & \text { L } & 24 & 61\end{array}$

Muscle \& Nerve, Vol 49, No. 2 (November 2013): pg. 225-232. DOI. This article is (C Wiley and permission has been granted for this version to appear in e-Publications@Marquette. Wiley does not grant permission for this article to be further copied/distributed or hosted elsewhere without the express permission from Wiley. 


\section{Test Apparatus and Experimental Setup}

Participants were assisted into a customized leg robot $\frac{46,48}{}$ (Kollmorgen, Northampton, Massachusetts). For each trial, force transducers (S. Himmelstein and Company, Hoffman Estates, Illinois) measured hip flexion and extension torques bilaterally ("test" leg and "contralateral" leg). The "test" leg is defined as the leg that generated the target hip flexion torque during each trial, whereas the contralateral leg was the leg during the same trial not designated to generate the target torque. Contralateral leg hip torques were quantified to determine potential differences in stabilizing or compensatory forces during the protocol. Bilateral knee and ankle joints were supported by the leg robot in a neutral position (15-20 flexion and $5^{\circ}$ of plantar flexion, respectively). Details on positioning of the test leg are described below. Custom written LabVIEW software (National Instruments, Austin, Texas) was used to time, control, present, and collect experimental data.

Joint torques and hip position data were low-pass filtered (500 $\mathrm{Hz}$ ) and sampled $(1,000 \mathrm{~Hz})$ using a data acquisition card (National Instruments Corp., Austin, Texas) and personal computer.

A 17-inch monitor (Samsung SyncMaster ${ }^{\mathrm{TM}}$ 740N, Samsung Electronics America, New Jersey) positioned 1 meter from the participant's head provided visual feedback of hip joint torques during isometric submaximal hip flexor trials (see Experimental Protocol below). A target torque scrolled horizontally in tandem with the participant's torque trace at $\sim 3 \mathrm{~cm} / \mathrm{s}$. The torque trace shown on the monitor was updated at $10 \mathrm{~Hz}$ using the median of a $100 \mathrm{~ms}$ window. The resolution of the visual gain was held constant at 100 pixels per Newton-meter of hip flexion torque, which, based on the size of the monitor, maintained a $\pm 5 \mathrm{Nm}$ window about the target torque across all trials and participants.

\section{Experimental Protocol}

Before testing, all participants attended a familiarization session to practice hip flexion contractions in the robotic device. First, the test leg was positioned at $20^{\circ}$ of hip flexion, and the contralateral hip was

Muscle \& Nerve, Vol 49, No. 2 (November 2013): pg. 225-232. DOI. This article is (C) Wiley and permission has been granted for this version to appear in e-Publications@Marquette. Wiley does not grant permission for this article to be further copied/distributed or hosted elsewhere without the express permission from Wiley. 
positioned at $0^{\circ}$. To account for torque contributions from gravitational forces (and not produced by the participant), brief baseline measurements were made of the weight of the leg and leg brace in the testing position. The estimated gravitational torque was removed from the recorded torque values, to represent the torques applied by the participant. $\frac{46,48}{} \mathrm{Next}$, participants performed at least 3 isometric hip flexion maximal voluntary contractions (MVCs) with each leg. Contractions were repeated (with a 1 min rest between contractions) until 2 consecutive MVCs produced peak values within $5 \%$ of the highest peak. Participants then performed a series of $10 \mathrm{~s}$ isometric hip flexion contractions at a specified load level: 5\%, 10\%, 15\%, 20\%, or $40 \%$ of the test leg MVC (see single participant data in Fig. 1). Each load condition was repeated 3 times. Trials were randomized by load level, leg tested (paretic vs. nonparetic), and repetition of a load level (total of 60 trials). Although only data from the control participants' dominant legs were analyzed, control participants performed the same number of trials as the participants with stroke to control for activity. Participants were given approximately 1 min rest between trials.
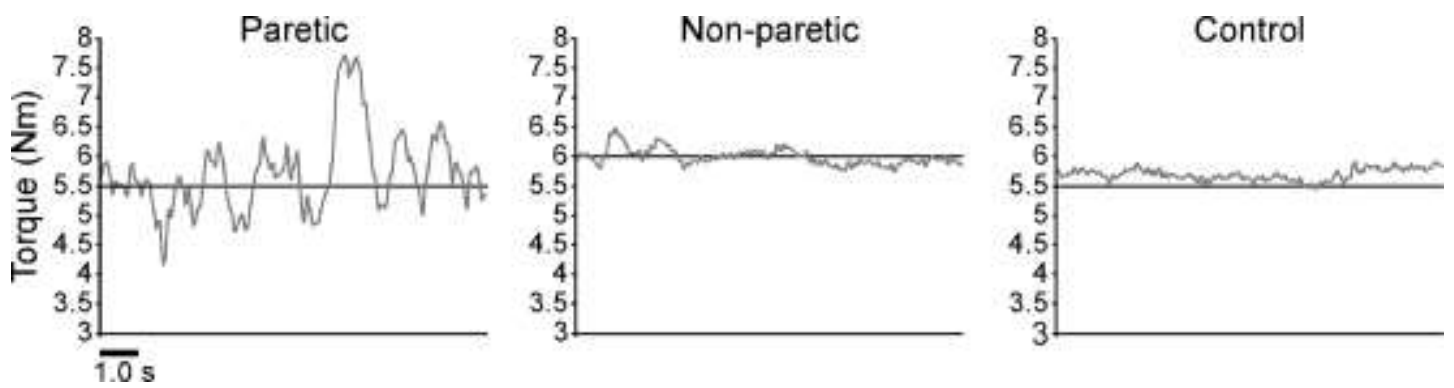

Figure 1. Single participant data of hip flexion torque traces at the $5 \%$ load level. The relative magnitude of torque fluctuations (coefficient of variation) and error from the target torque (root mean square error) were calculated as performance measures at each load. Frequency content of the torque signal (power density spectrum) was also analyzed.

At the beginning of each trial, participants were instructed to increase hip flexion until their torque trace was visible on the monitor. The $10 \mathrm{~s}$ of data collection began when the participant's torque trace intersected the target torque trace and the participant demonstrated a volitional correction. For all participants, this occurred within $3 \mathrm{~s}$ of an attempt. Throughout the trial duration, participants received verbal encouragement to "stay on the target line as best as possible."

Muscle \& Nerve, Vol 49, No. 2 (November 2013): pg. 225-232. DOI. This article is (C) Wiley and permission has been granted for this version to appear in e-Publications@Marquette. Wiley does not grant permission for this article to be further copied/distributed or hosted elsewhere without the express permission from Wiley. 
NOT THE PUBLISHED VERSION; this is the author's final, peer-reviewed manuscript. The published version may be accessed by following the link in the citation at the bottom of the page.

\section{Data Processing}

All joint torque and EMG values were processed using custom MATLAB programs (The MathWorks, Inc., Natick, Massachusetts). Hip torque data were zero-phase low-pass filtered $(100 \mathrm{~Hz})$ using a fourthorder Butterworth filter (filtfilt function in MATLAB).

\section{Data Analysis and Statistics}

Analysis of all torque data was performed on the last $10 \mathrm{~s}$ of each trial. Three of the participants with a history of stroke could not maintain the $40 \%$ target torque for the full $10 \mathrm{~s}$ in a total of 3 trials. For these 3 trials, data were analyzed for at least a $5 \mathrm{~s}$ portion of the trial. Steadiness, or the relative magnitude of the hip flexion torque fluctuations, was assessed using the coefficient of variation as a ratio ( $\mathrm{CV}=$ standard deviation of hip flexion torque/mean hip flexion torque). CV was calculated for both legs during each trial to quantify the steadiness of the test leg and also the contralateral leg. In other words, CV was considered a metric of the variability of the torque irrespective of overall offset from the target torque. Error of the torque (average net offset of hip flexion torque trace from the target torque) was quantified by the root mean square error (RMSE). RMSE was used as a metric of how accurately the individual could generate the target torque value and hence the error from the required torque. The equation used to calculate the RMSE of torque was:

$$
\begin{array}{r}
\text { RMSE }=\sqrt{\frac{\sum\left(X-X_{i}\right)^{2}}{n}} ; \text { where } X=\text { mean torque, } \\
X_{i}=\text { target torque, }, \mathbf{n}=\text { number of samples: }
\end{array}
$$

The CV and RMSE of torque were averaged for the 3 trials associated with each load condition for each leg. In addition to reporting the absolute RMSE, we also normalized the RMSE to the mean torque for each trial and averaged across the 3 trials associated with each load condition for each leg.

To examine the frequency content of the hip flexion torque trace, the originally sampled hip torque data were low-pass filtered $(20 \mathrm{~Hz})$ with a fourth-order Butterworth filter for a power spectral

Muscle \& Nerve, Vol 49, No. 2 (November 2013): pg. 225-232. DOI. This article is (C Wiley and permission has been granted for this version to appear in e-Publications@Marquette. Wiley does not grant permission for this article to be further copied/distributed or hosted elsewhere without the express permission from Wiley. 
density analysis. The power spectral density of the torque trace was estimated using the Welch method ( $p$ welch in MATLAB) with a nonoverlapping window of $2^{13}$ (8192), resulting in a frequency resolution of $0.122 \mathrm{~Hz}$. The power spectral density estimates were divided into 4 frequency bins $(0.1-1 \mathrm{~Hz}, 1-3 \mathrm{~Hz}, 3-7 \mathrm{~Hz}$, and 7-15 $\mathrm{Hz}$ ), and calculated as a percentage of the total power from 0.1-15 $\mathrm{Hz} . \underline{49}$

Data are reported as mean \pm standard deviation. A one-way analysis of variance (ANOVA) was used to detect differences between the paretic, nonparetic, and control leg baseline hip flexion MVC torques. Significance was accepted at $P<0.05$. Separate multifactor one-way ANOVAs were used to compare test leg type (paretic, nonparetic, and control) and load level (5\%,10\%, 15\%, 20\%, and $40 \%$ MVC) for the respective dependent variables of CV, RMSE, and normalized RMSE of the torque. A Tukey post hoc analysis was used for pairwise comparisons. Significance was accepted at $P<0.05$. Oneway ANOVAs were used to detect differences between the paretic, nonparetic, and control legs for the CV of the contralateral leg (i.e., nontest leg) for the $5 \%$ loading condition. A Tukey post hoc analysis was used for pairwise comparisons (significance accepted at $P<0.05$ ). For the power spectral density analysis of the torque data, separate one-way repeated measure ANOVAs were conducted for each of the 4 frequency bins on the paretic leg data to detect differences in percent area of power between load levels (5\%, 10\%, 15\%, 20\%, and $40 \%$ MVC). Tukey post hoc analysis was used for pairwise comparisons (significance accepted at $P<0.05$ ). The Pearson product-moment correlation coefficient was used to determine associations between torque metrics (MVC, CV, RMSE) and clinical measures of function (Ten Meter Walk Test and Berg Balance Scale).

\section{Results}

\section{Maximal Voluntary Hip Flexion Contraction Measurements}

Control leg MVC $(133 \pm 38 \mathrm{Nm})$ was larger than the nonparetic and paretic legs $(P \leq 0.003)$. For each individual with stroke, the paretic hip flexion MVC torque was less than the nonparetic MVC, and

Muscle \& Nerve, Vol 49, No. 2 (November 2013): pg. 225-232. DOI. This article is @ Wiley and permission has been granted for this version to appear in e-Publications@Marquette. Wiley does not grant permission for this article to be further copied/distributed or hosted elsewhere without the express permission from Wiley. 
the group average of paretic hip flexion MVC was less $(73 \pm 21 \mathrm{Nm}$ ) than the nonparetic ( $88 \pm 20 \mathrm{Nm}$ ), but it was not statistically significant $(P=0.4)$.

\section{Relative Magnitude of Torque Fluctuations}

Across all load levels, the CV was largest for the paretic leg $(0.11 \pm 0.03)$, followed by the nonparetic leg $(0.07 \pm 0.02)$, and smallest in the control leg $(0.03 \pm 0.007)$ (Fig. 2, main effect for leg, $P<0.001$; post hoc tests: paretic versus control, $P<0.001$; paretic versus nonparetic, $P=0.045$; nonparetic versus controls, $P=0.043$ ). There was a significant interaction between load level and leg $(P<0.05)$, whereby the paretic leg had significantly greater CV at the $5 \%$ load level than other loads, but the CV for the nonparetic and control legs showed similar values to the higher loads (Fig. 2).

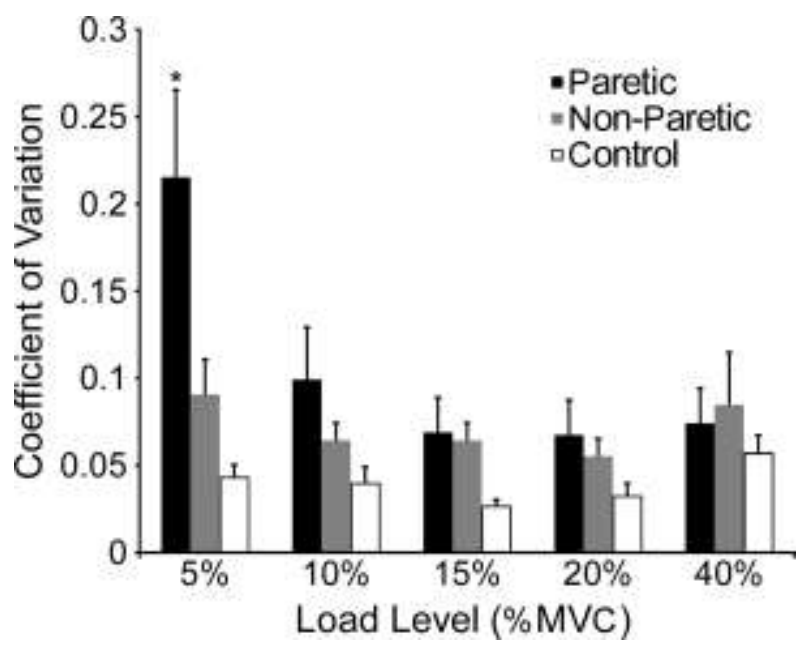

Figure 2. Group means \pm standard error of the coefficient of variation (CV) (ratio) for the paretic (black), nonparetic (gray), and control (white) legs at each of the load level conditions (percent of maximal voluntary contraction [MVC]). As a main effect, the magnitude of CV varied as follows: - paretic nonparetic $\square$ control. There was an interaction between the leg and load condition where the paretic leg CV was largest at the $5 \%$ load condition.

\section{Error of Torque}

There was a main effect of load for the magnitude of mean error (RMSE) from the target torque (RMSE, see the Materials and Methods section) but no main effect of leg (paretic vs. nonparetic vs. control, $P>0.05)$. The RMSE was significantly larger at the $40 \%$ MVC load level 
$(2.9 \pm 0.3 \mathrm{Nm}, P<0.05)$, compared with the error at lower loads, including $5 \%(0.6 \pm 0.3 \mathrm{Nm}), 10 \%(0.9 \pm 0.3 \mathrm{Nm}), 15 \%(0.7 \pm 0.3$ $\mathrm{Nm})$, and $20 \%(1.0 \pm 0.3 \mathrm{Nm})$. There was no significant difference in RMSE among the lower load levels and no interaction effects. When the RMSE was normalized to the target torque, there were no main effects for leg $(P=0.11)$, load $(P=0.127)$, and no interactions (leg $\times$ load $P=0.869$ ).

\section{Frequency Content of the Torque Fluctuations}

We compared the frequency content of the paretic leg force fluctuations at the $5 \%$ load condition with the other load conditions in each of the respective frequency bands (Fig. $\underline{3}$ ). In the lowest frequency band, the $5 \%$ load had the lowest percent area of power compared with the other load levels (Fig. $3 ; P<0.05$ ), and no other significant differences between other loads were detected by post hoc analysis. There were no significant differences between percent area of power for the respective load levels for the $1-3 \mathrm{~Hz}$ or $3-7 \mathrm{~Hz}$ frequency bands $(P>0.05)$. In the $7-15 \mathrm{~Hz}$ frequency band, the percent area of power was significantly higher for the $5 \%$ load than the other load levels $(P<0.05)$, and no other significant differences between other load levels were detected by post hoc analysis.

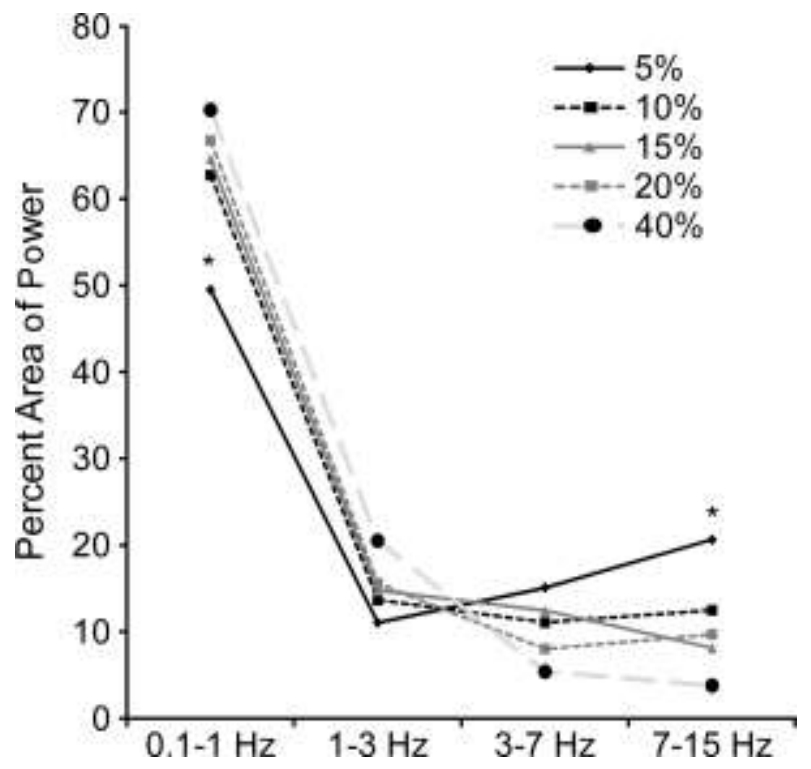

Figure 3. Percent area of frequency power for each load level in each frequency bin. Note that at the $5 \%$ load level there is less power in the lowest frequency bin and more power in the $7-15 \mathrm{~Hz}$ bin.

Muscle \& Nerve, Vol 49, No. 2 (November 2013): pg. 225-232. DOI. This article is (C) Wiley and permission has been granted for this version to appear in e-Publications@Marquette. Wiley does not grant permission for this article to be further copied/distributed or hosted elsewhere without the express permission from Wiley. 


\section{Force Fluctuations in the Contralateral Leg}

At the $5 \%$ load, the CV of the hip torque of the contralateral control leg (i.e., leg not being tested) was smaller compared with the paretic and nonparetic contralateral legs (Fig. 4). In other words, when the paretic leg was maintaining the $5 \%$ load, the contralateral leg (i.e., the nonparetic leg) generated larger torque fluctuations compared with the contralateral control leg.

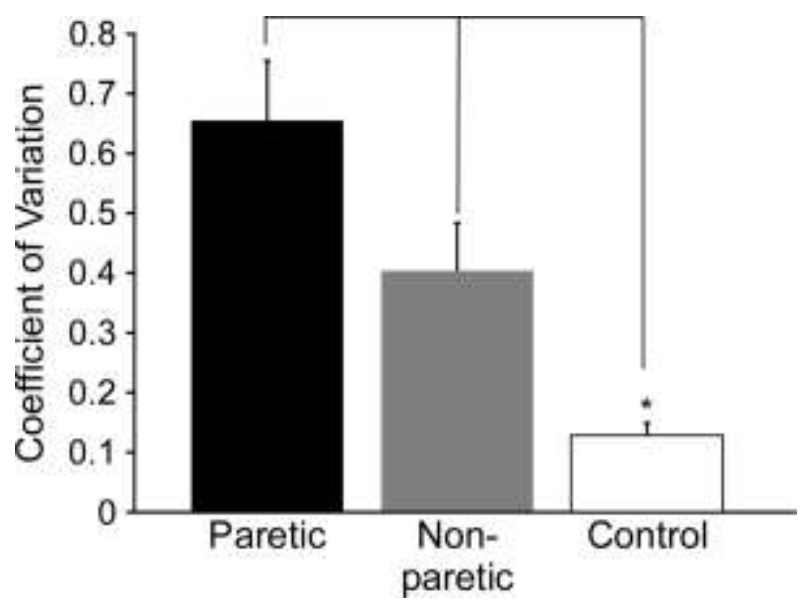

Figure 4. Group averages of the coefficient of variation (CV) for the contralateral leg at the $5 \%$ load level. The control leg had significantly smaller CV as compared to the nonparetic and control legs $(* P<0.05)$.

\section{MVC and CV Correlations with Clinical Measurements}

Paretic and nonparetic hip flexor MVC torques did not correlate significantly with comfortable walking speed $\left(r^{2}=0.13,0.02\right.$, respectively), Fugl Meyer $\left(r^{2}=0.07,0.02\right.$, respectively), and Berg Balance Score $\left(r^{2}=0.24,0.08\right.$, respectively). Paretic CV of torque for the $5 \%$ load was correlated negatively with comfortable walking speed (Ten Meter Walk Test) and the Berg Balance Scale (Fig. $\underline{5} ; r^{2}=0.54$ and 0.4 , respectively; $P<0.05)$. Thus, those participants with stroke who had a larger CV of torque, walked more slowly, and had lower balance scores. Paretic CV of torque at all other load levels did not correlate significantly with measures of Fugl Meyer, Berg Balance Score, or comfortable walking speed except for CV at 20\% MVC and comfortable walking speed $\left(r^{2}=0.39 ; P<0.05\right)$. The CV of torque of the nonparetic leg did not vary systematically with walking speed or balance (Fig. 므). 
NOT THE PUBLISHED VERSION; this is the author's final, peer-reviewed manuscript. The published version may be accessed by following the link in the citation at the bottom of the page.
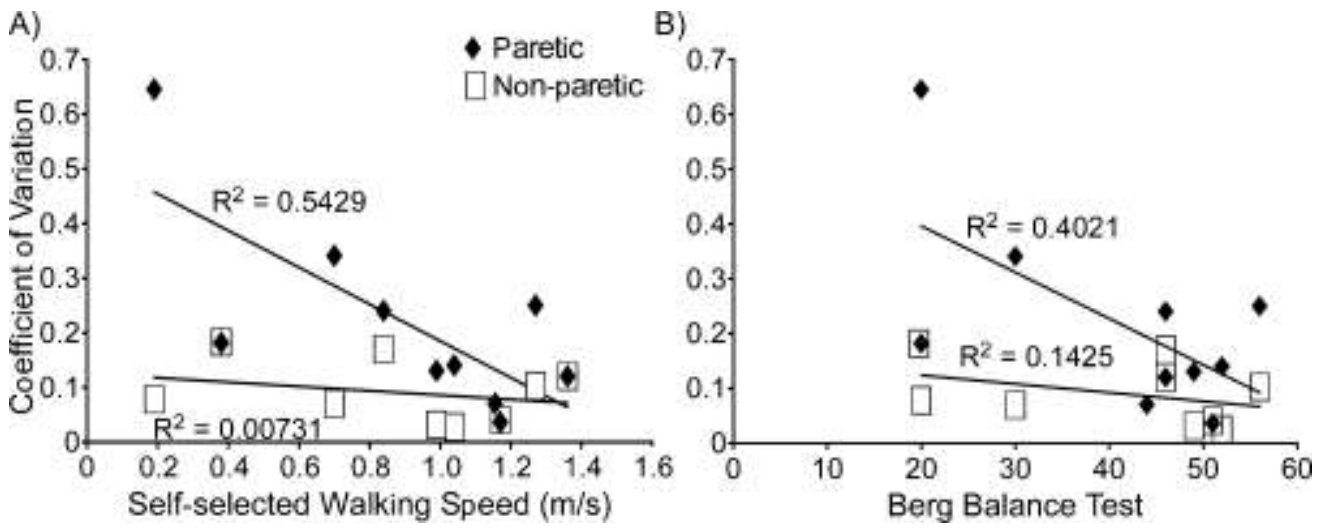

Figure 5. Associations between the paretic and nonparetic hip flexor $\mathrm{CV}$ at the $5 \%$ load and self-selected walking speed (A) and Berg Balance Score (B). Participants with larger torque fluctuations in their paretic leg walked slower and had worse balance $(P<0.05)$. The associations for the nonparetic leg were not significant $(P>0.05)$.

\section{Discussion}

The novel findings of this study are that for sustained hip flexion torques: (1) participants with a history of stroke were less steady (greater torque fluctuations, CV) for the paretic and nonparetic leg than controls; (2) the greatest deficits in CV for participants with a history of stroke occurred for the paretic leg at lowest tested load level; and (3) steadiness of the paretic leg at the lowest load level was associated negatively with functional measures of self-selected walking speed and balance. Diminished hip flexion steadiness of the paretic leg at the $5 \%$ MVC load was accompanied by higher variation of forces in the contralateral leg and a higher frequency component to the torque frequency profile. Deficits in force regulation with stroke could not be attributed to overall weakness of the paretic hip flexors (i.e., magnitude of baseline MVC) because: (1) the magnitudes of the MVC were not significantly different between leg groups; (2) the deficits for the participants with history of stroke occurred during the very low forces; and (3) participants with history of stroke had fewer differences in steadiness relative to controls at higher torque levels. Furthermore, the mean error from the target torque of the paretic leg, although large, was not different from the nonparetic and control legs. Consequently, while the loss of steadiness and motor control was apparent within participants with history of stroke, their overall accuracy (error from torque) was not impaired during an isometric contraction (when visual feedback was provided). This suggests that

Muscle \& Nerve, Vol 49, No. 2 (November 2013): pg. 225-232. DOI. This article is (C) Wiley and permission has been granted for this version to appear in e-Publications@Marquette. Wiley does not grant permission for this article to be further copied/distributed or hosted elsewhere without the express permission from Wiley. 
overall regulation of force in this study was not limited by the net magnitude of the descending signal (i.e., motoneuron pools were receiving enough excitation to achieve a given torque), because the participants with history of stroke were able to generate enough torque to achieve the target torque. Possible mechanisms are discussed below.

Poststroke, reduced resolution of control of motoneuron pools by supraspinal centers could contribute to decreased force regulation at the $5 \%$ level compared with the higher load levels seen in this study. Reduced resolution of control after stroke has been attributed to a loss of upper motoneurons innervating agonist spinal motoneuron pools and fewer lower motoneurons. $\frac{50-53}{1 n}$ the aging population, loss of lower motoneurons is associated with a compensatory increase in motor unit size as muscle fibers from dying motoneurons are reinnervated by surviving motoneurons. $\frac{54}{4}$ Therefore, due to a loss of both upper and lower motoneurons and a subsequent increase in motor unit size, error corrections would involve engagement of more motoneurons per given input, increasing the difficulty for agonist muscles to smoothly graduate small forces and result in greater CV of torque at lower loads as seen in this study.

Previous work in young healthy controls has attributed the modulation of low-force contractions to common descending synaptic drive. $\frac{55}{}$ However, in aging and neurologically involved populations synaptic noise may be influential as well. $\underline{56}$ Supraspinal pathways are known to actively inhibit spinal pathways and help focus relevant synaptic input to motoneurons. $\frac{57,58}{}$ This active filtering of synaptic inputs by supraspinal centers is likely impaired poststroke. Paretic motoneuron pools therefore would be subject to unfiltered spinal inputs or "noise" that could contribute to increased discharge variability and manifest as fluctuations with higher frequency content. In this study, the greater relative power (\%) in the higher frequency bin (Fig. 3 ) at the 5\% load compared with other load levels in the paretic leg is consistent with the contribution of relatively shorter latency spinal pathways to force fluctuations. Although not directly tested here, a potential source includes maladaptive synaptic input from the contralateral leg (Fig. 4 ) and is consistent with previous work that showed the influence of contralateral inputs following stroke ${ }^{46,59}$ and spinal cord injury. $\frac{60}{}$ In summary, the mechanism for loss of 
steadiness at all load levels in participants with stroke is likely to be mediated by higher cortical centers, because both the paretic and nonparetic sides were impaired relative to controls. However, the large loss of control at the lightest load tested (5\%) in the paretic leg compared with nonparetic and control legs is likely a combination of distorted supraspinal inputs (e.g., indicated with greater coactivation and contralateral leg variability) and maladaptive subcortical inputs (e.g., higher frequency content of the force fluctuations), which contribute to altered paretic hip flexor force regulation at low load levels. Future studies are required to examine how remodeling of motor unit function, such as changes in discharge rate variability at low loads, can impact steadiness of sustained force at low loads in people following stroke.

\section{Clinical Relevance: Relationship Between Paretic Hip Force Regulation and Function}

One of the most important and novel findings in this study was the associations between the steadiness at low loads and functional tasks in the participants with a history of stroke (Fig. $\underline{5}$ ). Given that many activities of daily living require control of submaximal forces by hip flexors, impaired submaximal force regulation would likely interfere with mobility. Much of the current evidence indicates that low force regulation (i.e., $<10 \% \mathrm{MVC}$ ) of the leg muscles is the best predictor of function in older adults compared with higher torques. $\underline{14-16}$ Thus following stroke, the functional relevance of impaired low-force regulation may be greater compared with the relationships seen in neurologically intact populations. Other factors in participants with history of stroke, however, such as the muscles involved or the functional measure used may also influence these associations. In the leg, for example, Chow and Stokic $\frac{32}{2}$ demonstrated impaired force regulation of paretic knee extensor muscles but no correlation with measures of leg function (2011). Here, we show a negative correlation between hip flexor control with walking speed and balance such that more functionally impaired participants with stroke were the least steady. These significant findings for the hip flexor muscles are consistent with previous associations between hip muscle deficits (in power and gross coordination) and leg function poststroke. $44,46,61,62$ Future studies are needed to understand deficits in force regulation in

Muscle \& Nerve, Vol 49, No. 2 (November 2013): pg. 225-232. DOI. This article is (C) Wiley and permission has been granted for this version to appear in e-Publications@Marquette. Wiley does not grant permission for this article to be further copied/distributed or hosted elsewhere without the express permission from Wiley. 
other muscles critical for walking and balance that are affected following stroke, such as the plantar flexors. With regards to treatment regimens, given the possible interference of sensory information at low loads, our data suggest that attention must be given to the use of sensory inputs during training protocols. Future studies are needed to address the role of sensory inputs (in particular spinal pathways versus visual inputs), force regulation, and leg function poststroke.

\section{Study Limitations}

There were several limitations to the study. With regard to the frequency analysis, we acknowledge that frequency content is not a direct measurement of the origins of the force fluctuations and could be related to other physiological phenomenon. Furthermore, because muscle synergy patterns of activation are often produced during volitional movements poststroke that result in out of sagittal plane force generation, $\stackrel{30,63}{ }$ quantifying accessory and synergist muscle recruitment and multijoint torque will provide valuable information on the role of these muscles during steadiness tasks. A final limitation of the study is the generalization of results to all time periods of recovery poststroke. The rate and magnitude of motor recovery is known to be the greatest during the first-year poststroke. However, because participants in our study sample were greater than 1-year poststroke, effects may be different in acute and subacute populations. Future studies are required to understand how submaximal force regulation can change between acute, subacute, and chronic phases of motor recovery.

\section{Acknowledgments}

The authors are very grateful to Dr. Brian D. Schmit for consultation on data analysis and use of equipment and to Dr. Tanya Onushko for her assistance with data analysis.

\section{References}

${ }^{1}$ Ahlsio B, Britton M, Murray V, Theorell T. Disablement and quality of life after stroke. Stroke 1984;15:886-890.

${ }^{2}$ Brashear A, Zafonte R, Corcoran M, Galvez-Jimenez N, Gracies JM, Gordon $M F$, et al. Inter- and intrarater reliability of the ashworth scale and the

Muscle \& Nerve, Vol 49, No. 2 (November 2013): pg. 225-232. DOI. This article is @ Wiley and permission has been granted for this version to appear in e-Publications@Marquette. Wiley does not grant permission for this article to be further copied/distributed or hosted elsewhere without the express permission from Wiley. 
NOT THE PUBLISHED VERSION; this is the author's final, peer-reviewed manuscript. The published version may be accessed by following the link in the citation at the bottom of the page.

disability assessment scale in patients with upper-limb poststroke spasticity. Arch Phys Med Rehabil 2002;83:1349-1354.

${ }^{3}$ Hankey GJ, Jamrozik K, Broadhurst RJ, Forbes S, Anderson CS. Long-term disability after first-ever stroke and related prognostic factors in the perth community stroke study, 1989-1990. Stroke 2002;33:10341040.

${ }^{4}$ Wade DT, Hewer RL. Functional abilities after stroke: measurement, natural history and prognosis. J Neurol Neurosurg Psychiatry 1987;50:177182.

${ }^{5}$ Perry J. Gait analysis. Thorofare: SLACK; 1992.

${ }^{6}$ Shumway-cook A, Woollacott MH. Motor control. New York: Lippincott, Williams and Wilkins; 2006.

${ }^{7}$ Bellew JW. The effect of strength training on control of force in older men and women. Aging Clin Exp Res 2002;14:35-41.

${ }^{8}$ Tracy BL. Force control is impaired in the ankle plantarflexors of elderly adults. Eur J Appl Physiol 2007;101:629-636.

${ }^{9}$ Tracy BL, Maluf KS, Stephenson JL, Hunter SK, Enoka RM. Variability of motor unit discharge and force fluctuations across a range of muscle forces in older adults. Muscle Nerve 2005;32:533-540.

${ }^{10}$ Tracy BL, Enoka RM. Older adults are less steady during submaximal isometric contractions with the knee extensor muscles. J Appl Physiol 2002; 92:1004-1012.

${ }^{11}$ Tracy BL, Dinenno DV, Jorgensen B, Welsh SJ. Aging, visuomotor correction, and force fluctuations in large muscles. Med Sci Sports Exerc 2007;39:469-479.

${ }^{12}$ Christou EA, Zelent M, Carlton LG. Force control is greater in the upper compared with the lower extremity. J Mot Behav 2003;35:322-324.

${ }^{13}$ Grunte I, Hunter GR, McCurry BD, Bolding MS, Roy JL, McCarthy JP. Age and gender differences in hip extension and flexion torque steadiness. Gerontology 2010;56:533-541.

${ }^{14}$ Seynnes O, Hue OA, Garrandes F, Colson SS, Bernard PL, Legros P, et al. Force steadiness in the lower extremities as an independent predictor of functional performance in older women. $J$ Aging Phys Act $2005 ; 13: 395-408$.

${ }^{15}$ Carville SF, Perry MC, Rutherford OM, Smith IC, Newham DJ. Steadiness of quadriceps contractions in young and older adults with and without a history of falling. Eur J Appl Physiol 2007;100:527-533.

${ }^{16}$ Kouzaki M, Shinohara M. Steadiness in plantar flexor muscles and its relation to postural sway in young and elderly adults. Muscle Nerve 2010;42:78-87.

${ }^{17}$ Tracy BL. Visuomotor contribution to force variability in the plantarflexor and dorsiflexor muscles. Hum Mov Sci 2007;26:796-807.

Muscle \& Nerve, Vol 49, No. 2 (November 2013): pg. 225-232. DOI. This article is (C) Wiley and permission has been granted for this version to appear in e-Publications@Marquette. Wiley does not grant permission for this article to be further copied/distributed or hosted elsewhere without the express permission from Wiley. 
NOT THE PUBLISHED VERSION; this is the author's final, peer-reviewed manuscript. The published version may be accessed by following the link in the citation at the bottom of the page.

${ }^{18}$ Marmon AR, Gould JR, Enoka RM. Practicing a functional task improves steadiness with hand muscles in older adults. Med Sci Sports Exerc 2011;43:1531-1537.

${ }^{19}$ Marmon AR, Pascoe MA, Schwartz RS, Enoka RM. Associations among strength, steadiness, and hand function across the adult life span. Med Sci Sports Exerc 2011;43:560-567.

${ }^{20}$ Wenzelburger R, Raethjen J, Loffler K, Stolze H, Illert M, Deuschl G. Kinetic tremor in a reach-to-grasp movement in parkinson's disease. Mov Disord 2000;15:1084-1094.

${ }^{21}$ Heldman DA, Jankovic J, Vaillancourt DE, Prodoehl J, Elble RJ, Giuffrida JP. Essential tremor quantification during activities of daily living. Parkinsonism Relat Disord 2011;17:537-542.

${ }^{22}$ Poon C, Robichaud JA, Corcos DM, Goldman JG, Vaillancourt DE. Combined measures of movement and force variability distinguish parkinson's disease from essential tremor. Clin Neurophysiol 2011;122:22682275.

${ }^{23}$ Hosseini $H$, Mandat T, Waubant E, Agid Y, Lubetzki C, Lyon-Caen O, et al. Unilateral thalamic deep brain stimulation for disabling kinetic tremor in multiple sclerosis. Neurosurgery 2012;70:66-69.

${ }^{24}$ Naderi $F$, Javadi SA, Motamedi M, Sahraian MA. The efficacy of primidone in reducing severe cerebellar tremors in patients with multiple sclerosis. Clin Neuropharmacol 2012;35:224-226.

${ }^{25}$ Milanov I, Georgiev D. Spasmodic torticollis and tremor due to multiple sclerosis: a case report. Funct Neurol 1995;10:281-285.

${ }^{26}$ McPherson JG, Ellis MD, Heckman CJ, Dewald JP. Evidence for increased activation of persistent inward currents in individuals with chronic hemiparetic stroke. J Neurophysiol 2008;100:3236-3243.

${ }^{27}$ Lawrence DG, Kuypers HG. The functional organization of the motor system in the monkey. I. The effects of bilateral pyramidal lesions. Brain 1968;91:1-14.

${ }^{28}$ Lawrence DG, Kuypers HG. The functional organization of the motor system in the monkey. Ii. The effects of lesions of the descending brain-stem pathways. Brain 1968;91:15-36.

${ }^{29}$ Dewald JP, Pope PS, Given JD, Buchanan TS, Rymer WZ. Abnormal muscle coactivation patterns during isometric torque generation at the elbow and shoulder in hemiparetic subjects. Brain 1995;118(Pt 2):495-510.

${ }^{30} \mathrm{Cruz} \mathrm{TH}$, Dhaher YY. Evidence of abnormal lower-limb torque coupling after stroke: an isometric study. Stroke 2008;39:139-147.

${ }^{31}$ Zaaimi B, Edgley SA, Soteropoulos DS, Baker SN. Changes in descending motor pathway connectivity after corticospinal tract lesion in macaque monkey. Brain 2012;135:2277-2289.

${ }^{32}$ Chow JW, Stokic DS. Force control of quadriceps muscle is bilaterally impaired in subacute stroke. J Appl Physiol 2011;111:1290-1295.

Muscle \& Nerve, Vol 49, No. 2 (November 2013): pg. 225-232. DOI. This article is (C) Wiley and permission has been granted for this version to appear in e-Publications@Marquette. Wiley does not grant permission for this article to be further copied/distributed or hosted elsewhere without the express permission from Wiley. 
NOT THE PUBLISHED VERSION; this is the author's final, peer-reviewed manuscript. The published version may be accessed by following the link in the citation at the bottom of the page.

${ }^{33}$ Hiebert GW, Whelan PJ, Prochazka A, Pearson KG. Contribution of hind limb flexor muscle afferents to the timing of phase transitions in the cat step cycle. J Neurophysiol 1996;75:1126-1137.

${ }^{34}$ Grillner S, Rossignol S. On the initiation of the swing phase of locomotion in chronic spinal cats. Brain Res 1978;146:269-277.

${ }^{35}$ Kriellaars DJ, Brownstone RM, Noga BR, Jordan LM. Mechanical entrainment of fictive locomotion in the decerebrate cat. J Neurophysiol 1994;71:2074-2086.

${ }^{36}$ Lam T, Pearson KG. Proprioceptive modulation of hip flexor activity during the swing phase of locomotion in decerebrate cats. J Neurophysiol 2001;86:1321-1332.

${ }^{37}$ Nadeau S, Arsenault AB, Gravel D, Bourbonnais D. Analysis of the clinical factors determining natural and maximal gait speeds in adults with a stroke. Am J Phys Med Rehabil 1999;78:123-130.

${ }^{38}$ Milot MH, Nadeau S, Gravel D. Muscular utilization of the plantarflexors, hip flexors and extensors in persons with hemiparesis walking at selfselected and maximal speeds. J Electromyogr Kinesiol 2007;17:184193.

${ }^{39}$ Dean JC, Kuo AD. Elastic coupling of limb joints enables faster bipedal walking. J R Soc Interface 2009;6:561-573.

${ }^{40}$ Bisson EJ, McEwen D, Lajoie Y, Bilodeau M. Effects of ankle and hip muscle fatigue on postural sway and attentional demands during unipedal stance. Gait Posture. 33:83-87.

${ }^{41}$ Lehmann JF. Biomechanics of ankle-foot orthoses: prescription and design. Arch Phys Med Rehabil 1979;60:200-207.

${ }^{42}$ Peterson CL, Kautz SA, Neptune RR. Muscle work is increased in pre-swing during hemiparetic walking. Clin Biomech (Bristol, Avon) 2011;26:859-866.

${ }^{43}$ Nadeau S, Gravel D, Arsenault AB, Bourbonnais D. Plantarflexor weakness as a limiting factor of gait speed in stroke subjects and the compensating role of hip flexors. Clin Biomech (Bristol, Avon) 1999; $14: 125-135$.

${ }^{44}$ Jonkers I, Delp S, Patten C. Capacity to increase walking speed is limited by impaired hip and ankle power generation in lower functioning persons post-stroke. Gait Posture 2009;29:129-137.

${ }^{45}$ Neckel ND, Blonien N, Nichols D, Hidler J. Abnormal joint torque patterns exhibited by chronic stroke subjects while walking with a prescribed physiological gait pattern. J Neuroeng Rehabil 2008;5:19.

${ }^{46}$ Hyngstrom A, Onushko T, Chua M, Schmit BD. Abnormal volitional hip torque phasing and hip impairments in gait post stroke. J Neurophysiol 2010;103:1557-1568.

Muscle \& Nerve, Vol 49, No. 2 (November 2013): pg. 225-232. DOI. This article is (C) Wiley and permission has been granted for this version to appear in e-Publications@Marquette. Wiley does not grant permission for this article to be further copied/distributed or hosted elsewhere without the express permission from Wiley. 
NOT THE PUBLISHED VERSION; this is the author's final, peer-reviewed manuscript. The published version may be accessed by following the link in the citation at the bottom of the page.

${ }^{47}$ Kriska AM, Bennett $\mathrm{PH}$. An epidemiological perspective of the relationship between physical activity and NIDDM: from activity assessment to intervention. Diabetes Metab Rev 1992;8:355-372.

${ }^{48}$ Onushko T, Schmit BD. Reflex response to imposed bilateral hip oscillations in human spinal cord injury. J Neurophysiol 2007;98:1849-1861.

${ }^{49}$ Taylor AM, Christou EA, Enoka RM. Multiple features of motor-unit activity influence force fluctuations during isometric contractions. $J$ Neurophysiol 2003;90:1350-1361.

${ }^{50}$ Lang CE, Wagner JM, Bastian AJ, Hu Q, Edwards DF, Sahrmann SA, Dromerick AW. Deficits in grasp versus reach during acute hemiparesis. Exp Brain Res 2005;166:126-136.

${ }^{51}$ Schieber $\mathrm{MH}$, Lang $\mathrm{CE}$, Reilly $\mathrm{KT}$, McNulty $\mathrm{P}$, Sirigu A. Selective activation of human finger muscles after stroke or amputation. Adv Exp Med Biol 2009;629:559-575.

${ }^{52} \mathrm{Li} X$, Wang YC, Suresh NL, Rymer WZ, Zhou P. Motor unit number reductions in paretic muscles of stroke survivors. IEEE Trans Inf Technol Biomed 2011;15:505-512.

${ }^{53}$ Hara Y, Masakado Y, Chino N. The physiological functional loss of single thenar motor units in the stroke patients: when does it occur? Does it progress? Clin Neurophysiol 2004;115:97-103.

${ }^{54}$ Reeves ND, Narici MV, Maganaris CN. Musculoskeletal adaptations to resistance training in old age. Man Ther 2006;11:192-196.

${ }^{55}$ Negro F, Holobar A, Farina D. Fluctuations in isometric muscle force can be described by one linear projection of low-frequency components of motor unit discharge rates. J Physiol 2009;587:5925-5938.

${ }^{56}$ Enoka RM, Christou EA, Hunter SK, Kornatz KW, Semmler JG, Taylor AM, Tracy BL. Mechanisms that contribute to differences in motor performance between young and old adults. J Electromyogr Kinesiol 2003; 13:1-12.

${ }^{57}$ Jankowska E. Interneuronal relay in spinal pathways from proprioceptors. Prog Neurobiol 1992;38:335-378.

${ }^{58}$ Thompson AK, Chen XY, Wolpaw JR. Acquisition of a simple motor skill: task-dependent adaptation plus long-term change in the human soleus h-reflex. J Neurosci 2009;29:5784-5792.

${ }^{59}$ Kautz SA, Patten C, Neptune RR. Does unilateral pedaling activate a rhythmic locomotor pattern in the nonpedaling leg in post-st.roke hemiparesis? J Neurophysiol 2006;95:3154-3163.

${ }^{60}$ Ferris DP, Gordon KE, Beres-Jones JA, Harkema SJ. Muscle activation during unilateral stepping occurs in the nonstepping limb of humans with clinically complete spinal cord injury. Spinal Cord 2004;42:14-23.

${ }^{61} \mathrm{Cruz} \mathrm{TH}$, Lewek MD, Dhaher YY. Biomechanical impairments and gait adaptations post-stroke: multi-factorial associations. J Biomech 2009;42:1673-1677.

Muscle \& Nerve, Vol 49, No. 2 (November 2013): pg. 225-232. DOI. This article is (C) Wiley and permission has been granted for this version to appear in e-Publications@Marquette. Wiley does not grant permission for this article to be further copied/distributed or hosted elsewhere without the express permission from Wiley. 
NOT THE PUBLISHED VERSION; this is the author's final, peer-reviewed manuscript. The published version may be accessed by following the link in the citation at the bottom of the page.

${ }^{62} \mathrm{Hsu} \mathrm{AL}$, Tang PF, Jan $\mathrm{MH}$. Analysis of impairments influencing gait velocity and asymmetry of hemiplegic patients after mild to moderate stroke. Arch Phys Med Rehabil 2003;84:1185-1193.

${ }^{63}$ Ellis MD, Holubar BG, Acosta AM, Beer RF, Dewald JP. Modifiability of abnormal isometric elbow and shoulder joint torque coupling after stroke. Muscle Nerve 2005;32:170-178. 